\title{
The effect of pregnancy on survival in a low-grade glioma cohort
}

\author{
Pål A. Rønning, MD, ${ }^{1}$ Eirik Helseth, MD, PhD, ${ }^{1}$ Torstein R. Meling, MD, PhD, ${ }^{1}$ and \\ Tom B. Johannesen, MD, PhD² \\ 1Department of Neurosurgery, Oslo University Hospital; and ${ }^{2}$ Cancer Registry of Norway, Oslo, Norway
}

OBJECTIVE The impact of pregnancy on survival in female patients with low-grade glioma (LGG) is unknown and controversial. The authors designed a retrospective cohort study on prospectively collected registry data to assess the influence of pregnancy and child delivery on the survival of female patients with LGG.

METHODS In Norway, the reporting of all births and cancer diagnoses to the Medical Birth Registry of Norway (MBRN) and the Cancer Registry of Norway (CRN), respectively, is compulsory by law. Furthermore, every individual has a unique 11-digit identification number. The CRN was searched to identify all female patients with a histologically confirmed diagnosis of World Health Organization (WHO) Grade II astrocytoma, oligoastrocytoma, oligodendroglioma, or pilocytic astrocytoma who were 16-40 years of age at the time of diagnosis during the period from January 1, 1970, to December 31, 2008. Obstetrical information was obtained from the MBRN for each patient. The effect of pregnancy on survival was evaluated using a Cox model with parity as a time-dependent variable.

RESULTS The authors identified 65 patients who gave birth to 95 children after an LGG diagnosis. They also identified 281 patients who did not give birth after an LGG diagnosis. The median survival was 14.3 years $(95 \% \mathrm{Cl} 11.7-20.6$ years) for the entire study population. The effect of pregnancy was insignificant in the multivariate model (HR $0.71,95 \%$ $\mathrm{Cl}$ 0.35-1.42).

CONCLUSIONS Pregnancy does not seem to have an impact on the survival of female patients with LGG.

http://thejns.org/doi/abs/10.3171/2015.6.JNS15985

KEY WORDS glioma; neurooncology; pregnancy; oncology

A DULT low-grade gliomas (LGGs; World Health Organization [WHO] Grade II) are progressive brain tumors with diffuse borders against normal brain tissue and have a propensity to spread in an infiltrative manner throughout the brain. ${ }^{16}$ These tumors demonstrate a tendency to evolve into more aggressive highgrade gliomas (HGGs). WHO Grade I tumors are also usually termed "LGG." However, the nature of these lesions is quite different from their Grade II counterpart in that the Grade I tumor is not infiltrative and usually demonstrates more compact growth characteristics, making it more amenable to complete resection. LGGs compose approximately $15 \%$ of all gliomas. ${ }^{26}$ Patients most often present with seizures, but they can also demonstrate neurological and cognitive deficits or complain of headache.,26 There is a clear tendency for patients with these tumors to present earlier in life than those with higher-grade tumors, with the median age at diagnosis being between 40 and 50 years. ${ }^{11}$

Therefore, female patients are often diagnosed with LGG while within their reproductive years. As clinicians, we are often questioned and expected to counsel female patients on the issue of how pregnancy and delivery affects the biology of their LGG and, ultimately, their own survival. To our knowledge, only 2 other reports detail the effects of pregnancy on patients with LGG. These reports originate from the French glioma study group and feature information on the clinical symptoms and speed of tumor growth in 11 patients and 12 pregnancies..$^{19,21}$ The results indicate that there is a peri-gestational increase in lesion growth rates witnessed on MR images. However, is it still unknown how this affects outcome and survival.

Since patients often present with seizures, they are

ABBREVIATIONS CRN = Cancer Registry of Norway; HGG = high-grade glioma; ICD-O-3 = International Classification of Diseases for Oncology, third revision; LGG = low-grade glioma; MBRN = Medical Birth Registry of Norway; VDE = velocity of diametric expansion.

SUBMITTED April 29, 2015. ACCEPTED June 18, 2015.

INCLUDE WHEN CITING Published online January 1, 2016; DOI: 10.3171/2015.6.JNS15985. 
frequently started on anticonvulsant medication. Anticonvulsants are probably associated with birth defects, although the effect is dependent on the type of anticonvulsant, the dose, and whether the anticonvulsant is part of mono- or polytherapy. ${ }^{1}$ Hence, this is also an important issue to be cognizant of when advising young female patients on pregnancy issues.

Thus, the aim of this study was to investigate how pregnancy impacts survival in female patients with LGG. Moreover, the rate of epilepsy in patients with LGG and the rate of birth defects in their offspring were addressed.

\section{Methods}

Norway has a well-defined population of 5.1 million (August 2013), and each individual has a unique 11-digit identification number, allowing for individual follow-up at a population level. In this study, we linked 2 prospectively maintained national databases: the Cancer Registry of Norway (CRN) and the Medical Birth Registry of Norway (MBRN).

The CRN was founded in 1951 and maintains a prospective database on all neoplasms diagnosed in Norway. For the central nervous system, it includes both malignant and benign tumors. Reporting to the registry is compulsory by law and is based on clinical reports, pathology reports, and information from death certificates reporting neoplastic disease. The quality of the registry is maintained by ensuring that missing reports from attending clinicians or pathologists are requested by direct contact. When multiple operations are performed on the same patient and generate multiple histological specimens, the database is updated accordingly. The histology of the neoplasms in this time period is coded according to the International Classification of Diseases for Oncology, third revision (ICD-O-3). Data from the CRN have undergone quality control and are valid for population studies., ${ }^{9,12}$ The registry also electronically retrieves from all centers nationwide data on radiotherapy treatment, ensuring complete information on the radiation dose and fractions prescribed in all patients.

The MBRN was founded in 1967 and prospectively collects information on all births after 12 weeks of gestation. Information on maternal health and demographic variables are included, as is information regarding parturition and the postnatal health of the infant. Reporting to this registry is also compulsory by law and is done via notification forms filled in by the attending midwife or obstetrician. The quality of this registry has proven to be good. ${ }^{6}$

The CRN database search was performed by selecting female individuals with brain tumors who were between the ages of 16 and 40 years at the time of their diagnosis during the time period from January 1, 1970, to December 31,2008 . Subsequently, these women were matched with records in the MBRN, and thus adding information about parity. Finally, we identified the women with LGG according to the first 4 digits in the ICD-O-3 code (astrocytoma 9400, 9410, 9411, 9420; oligoastrocytoma 9382; oligodendroglioma 9450; and pilocytic astrocytoma 9421). Other WHO Grade I or II histological entities were considered too rare to be included for further analysis.
Only 1 patient emigrated during the study period and was censored at the time of emigration. All the remaining patients had complete follow-up data.

\section{Ethics}

The study was approved by the data protection officers at the CRN and the MBRN.

\section{Statistics}

Summary statistics are given as means and medians with 95\% confidence intervals and interquartile ranges (IQR) as appropriate. The total study population was divided into 2 groups: 1) patients who gave birth after diagnosis, and 2) patients who did not deliver any children after diagnosis. The groups were compared using the chisquared test and Mann-Whitney U-test. For the survival analysis, we used a Cox regression model where parity and, therefore, the time between diagnosis and parturition was entered as a time-varying covariate. This timevarying covariate allowed the variable to reflect the actual time in the different parity groups and is necessary when the variable changes value under the time of follow-up. This ensures that the analysis properly mirrors the patient parity status according to the time after diagnosis. The Cox regression model was repeated after excluding Grade I gliomas to ascertain any differences between the Grade I and II tumors. The variables in the Cox model are presented by both univariate and multivariate models. The survival data are presented as a Cox model and as an event history graph where the individual patients with their survival and their parity status are visualized. ${ }^{5}$ Median survival was calculated using the Kaplan-Meier estimator for the entire sample.

The rate of epilepsy associated with LGG was determined using a chi-squared test by comparing the rate of epilepsy during pregnancy in the cohort giving birth before an LGG diagnosis with the rate of epilepsy in the cohort giving birth after an LGG diagnosis. A comparison in the rate of epilepsy before and after diagnosis was also made in women who gave birth both before and after their diagnosis by using McNemar's test.

$\mathrm{R}$ version 2.15.1 with the Hmisc, plyr and data.table packages were used for all statistical analysis.

\section{Results}

We identified a total of 346 women who were 16 to 40 years of age at the time of their confirmed histological diagnosis of LGG during the time period from January 1, 1970, to December 31, 2008. The median follow-up period was 15.2 years. A total of 469 children were delivered to women in this cohort of 346 LGG patients. However, 106 of these women were nulliparous. After diagnosis, 65 patients delivered a total of 95 children. A total of 374 children were delivered to women prior to their diagnosis; 175 women gave birth before diagnosis only, and 21 women gave birth both before ( 25 children) and after their diagnosis (25 children).

The women were divided into 2 groups contingent upon their postdiagnosis parity, and the characteristics of the 2 groups are presented in Table 1. The women who became 
pregnant after diagnosis tended to be younger at the time of diagnosis (median age 25.3 vs 31.4 years, $p<0.001$ ). Furthermore, adjuvant therapy was used in a higher proportion of the women who did not become pregnant as compared with patients who did become pregnant (radiation therapy: $24.6 \%$ vs $9.2 \%$, respectively, $\mathrm{p}<0.01$; chemotherapy: $10.3 \%$ vs $1.5 \%$, respectively, $\mathrm{p}=0.013$ ).

The distribution of patient age at diagnosis and the time of parturition for the patients subsequently giving birth is detailed in Fig. 1. The number of pregnancies ranged from 1 to 3 , and the patient age at diagnosis ranged from 16 to 36 years. The median time between diagnosis and first parturition was 4.2 years (IQR 2.1-6.6 years). A total of 11 patients in this group died within the study period and thus leaving 54 patients censored.

The calculated survival probability is presented along with the time-dependent parity status displayed in different colors (Fig. 2). The median survival for all patients in the cohort was 14.3 years (95\% CI 11.7-20.6 years). The 5 - and 10-year survival rates were $75.7 \%$ and $54.8 \%$, respectively (excluding patients censored before the 5- and 10 -year follow-ups). Dismissing the patients with pilocytic astrocytomas, we found the median survival to be 12.2 years (95\% CI 10.7-17.5 years) in our cohort.

In the unadjusted Cox model, we identified increasing

TABLE 1. Patient characteristics stratified by parity status

\begin{tabular}{|c|c|c|c|}
\hline \multirow[b]{2}{*}{ Parameter } & \multicolumn{2}{|c|}{ Parity After Diagnosis } & \multirow[b]{2}{*}{$\mathrm{p}$ Value } \\
\hline & 0 & $\geq 1$ & \\
\hline No. of patients & 281 & 65 & \\
\hline Histology & & & $0.435^{\star}$ \\
\hline Astrocytoma & $56.6 \%(159)$ & $56.9 \%(37)$ & \\
\hline Oligoastrocytoma & $7.5 \%(21)$ & $7.7 \%(5)$ & \\
\hline Oligodendroglioma & $23.8 \%(67)$ & $16.9 \%(11)$ & \\
\hline Pilocytic astrocytoma & $12.1 \%(34)$ & $18.5 \%(12)$ & \\
\hline Age at diagnosis in yrs & $26.2 / 31.4 / 36.2$ & $19.2 / 25.3 / 29.4$ & $<0.001 \ddagger$ \\
\hline Chemotherapy & & & $0.013^{*}$ \\
\hline No & $53.4 \%(150)$ & $70.8 \%(46)$ & \\
\hline Yes & $10.3 \%(29)$ & $1.5 \%(1)$ & \\
\hline Unknown & $36.3 \%(102)$ & $27.7 \%(18)$ & \\
\hline Surgery & & & $0.117^{*}$ \\
\hline Biopsy & $11.4 \%(32)$ & $3.1 \%(2)$ & \\
\hline Resection & $80.1 \%(225)$ & $89.2 \%(58)$ & \\
\hline Unknown & $8.5 \%(24)$ & $7.7 \%(5)$ & \\
\hline Radiation therapy & & & $0.007^{*}$ \\
\hline No & $75.4 \%(212)$ & $90.8 \%(59)$ & \\
\hline Yes & $24.6 \%(69)$ & $9.2 \%(6)$ & \\
\hline Parity after diagnosis & & & NA \\
\hline 0 & $100.0 \%(281)$ & $0.0 \%(0)$ & \\
\hline 1 & $0.0 \%(0)$ & $60.0 \%(39)$ & \\
\hline 2 & $0.0 \%(0)$ & $33.8 \%(22)$ & \\
\hline 3 & $0.0 \%(0)$ & $6.2 \%(4)$ & \\
\hline $\begin{array}{l}\text { NA = not applicable. } \\
\text { * Chi-squared test. } \\
\dagger \text { 25th percentile/median/75 } \\
\ddagger \text { Mann-Whitney U-test. }\end{array}$ & 5th percentile. & & \\
\hline
\end{tabular}

parity (HR 0.50, 95\% CI 0.25-0.99), decreasing age (HR $1.07,95 \%$ CI 1.04-1.09), and resection compared with biopsy (HR $0.54,95 \%$ CI $0.35-0.84$ ) to be associated with increased survival after diagnosis. Undergoing radiotherapy (HR 2.01, 95\% CI 1.45-2.80) at any time point after diagnosis was associated with decreased survival. Parity after diagnosis was associated with a protective effect in the unadjusted model (1 birth: HR 0.50, 95\% CI 2.53-0.99; 2 or more births: HR 0.20 , 95\% CI 0.05-0.83). However, after controlling for the impact of other variables in the adjusted Cox model, increasing parity was not significantly associated with improved survival (HR 0.71 , 95\% CI 0.35-1.42). Age and radiation therapy maintained their effect in the adjusted model (HR 1.05, 95\% CI 1.021.08 and HR 1.81, 95\% CI 1.26-2.59, respectively). After excluding patients with pilocytic astrocytomas from the analysis, results from the Cox model demonstrate similar coefficients as for the entire cohort. Further details can be found in Table 2.

Epilepsy during pregnancy was reported in 30 (31.6\%) of the 95 pregnancies that occurred after LGG diagnosis, but in only 10 of the pregnancies that occurred prior to diagnosis $(10 / 374=2.7 \%)$. Furthermore, among the women who were pregnant both before and after their diagnosis, only $1(4 \%)$ in 25 pregnancies occurring before diagnosis was associated with epilepsy, while 11 (44\%) of the 25 pregnancies after diagnosis were associated with epilepsy. Thus, LGG and/or the treatment for LGG seem to be associated with epilepsy during pregnancy $(\mathrm{p}<0.01)$. However, we did not observe any difference in fetal malformations between the 2 groups (4.2\% in the birth-after-diagnosis group vs $3.5 \%$ in the birth-before-diagnosis group, $\mathrm{p}=$ $0.70)$. With respect to the mode of delivery, there was a tendency toward more planned caesarean sections in the patients who were known to have LGG (11.5\%) compared with patients who gave birth before an LGG diagnosis (3.5\%; $\mathrm{p}=0.01)$. There was no difference between the 2 groups with respect to conversion of planned delivery mode $(\mathrm{p}=0.80)$. Further details can be found in Table 3 .

The Cox analysis was repeated using epilepsy in an unadjusted time-varying model both for the subset that gave birth after diagnosis and in the total population. Overall survival was not affected by epilepsy in either group ( $\mathrm{p}=$ 0.07 and $\mathrm{p}=0.28$, respectively).

\section{Discussion}

In the largest study on pregnancy and LGG reported so far, we identified pregnancy and child delivery as neither a positive nor a negative prognostic factor with regard to survival for fertile women diagnosed with LGG. Moreover, the rate of epilepsy during pregnancy is higher after patients are diagnosed with LGG (31.6\% vs $2.3 \%$ ), but the rate of birth defects is similar (4.2\% vs $4.6 \%)$.

To our knowledge only 2 other published studies have specifically investigated the issues of pregnancy and outcome in females with LGG. Both studies originate from the French glioma study group..$^{19,21}$ In the 2009 study, the authors reported that a possible negative interaction between tumor and pregnancy occurred in 6 of 8 patients. ${ }^{19}$ One year later, in 2010, another group of authors used the velocity of diametric expansion (VDE) technique to show 


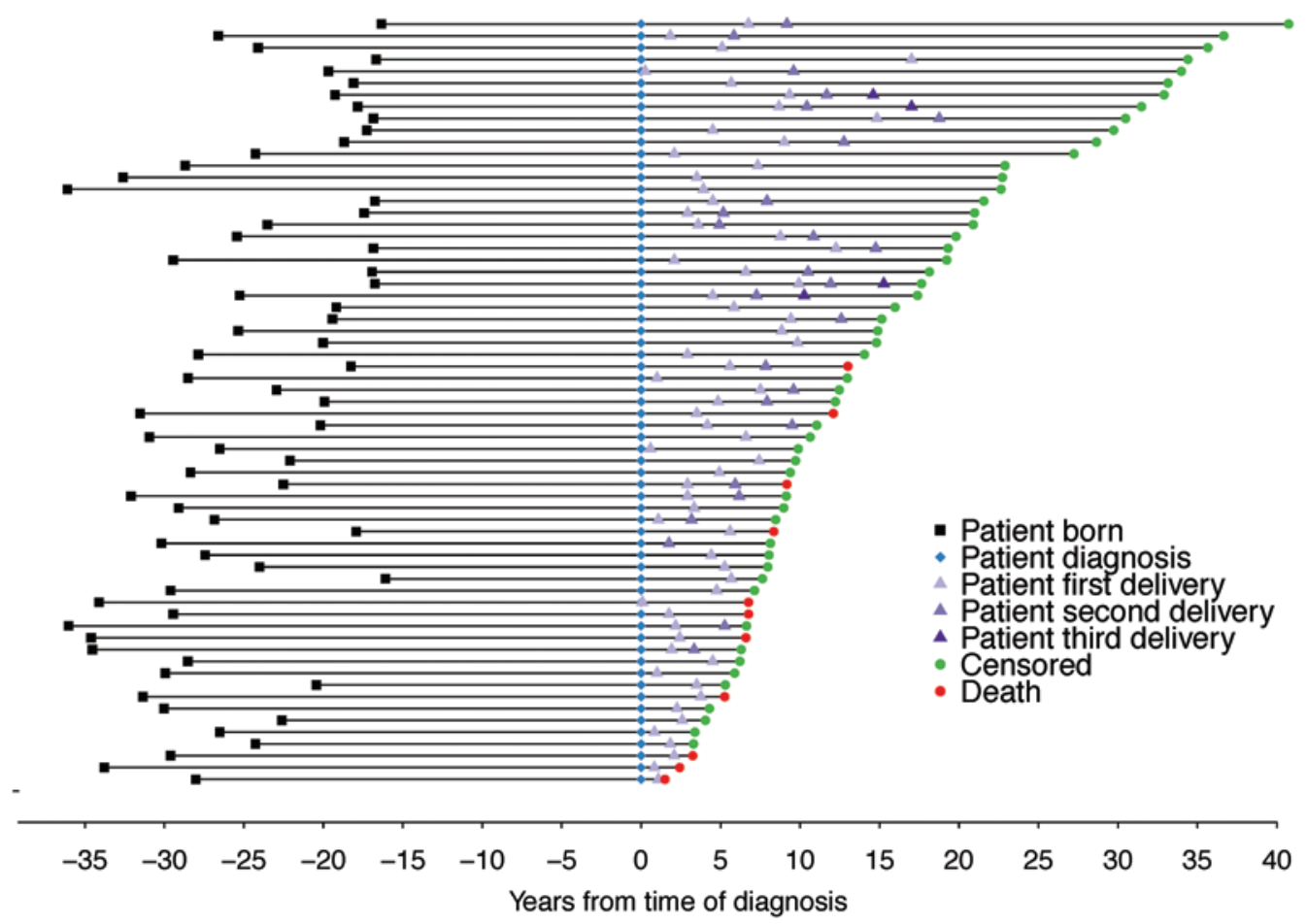

FIG. 1. This event chart details the patient age at diagnosis and the distribution of time between diagnosis and subsequent parity. Figure is available in color online only.

that tumor growth accelerates during pregnancy as compared with the tumor growth rate both pre- and postdelivery. ${ }^{21,22}$ Findings from the French glioma study group are not at odds with our results since the French study relates symptoms to MRI findings and does not assess how pregnancy and delivery affect survival. ${ }^{19}$ Furthermore, their

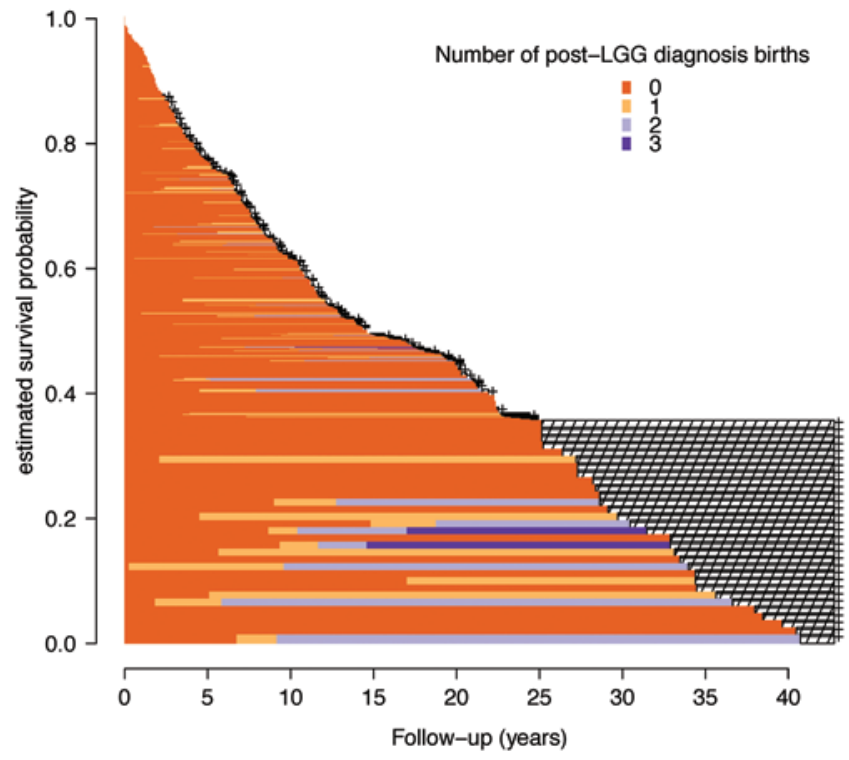

FIG. 2. This event history provides information on the time-varying nature of the patients' parity contrasted with the survival time of the patient. ${ }^{5}$ Hatched segments refer to censored individuals. Figure is available in color online only. finding of increased VDE during pregnancy can be interpreted as clinically nonsignificant with regard to overall survival given the results from our study and the return of VDE back to prepregnancy values after delivery.

A case series from Holland describes 7 patients who were diagnosed with LGG before pregnancy. ${ }^{33}$ The series showed that 2 patients had MRI tumor progression after pregnancy, 3 had symptomatic seizures during pregnancy, and $3 \mathrm{had}$ the pregnancies terminated. Unfortunately, the information provided does not allow any conclusions to be made regarding the effect of LGG on patient outcome.

Approximately $40 \%-90 \%$ of patients with LGG have epilepsy.,13,27 Thus, they often require prophylactic anticonvulsant medication. Anticonvulsants are known for their teratogenic effects and could be a major impediment for pregnancy, causing possible birth defects. ${ }^{28}$ We do not have specific information on the intake of anticonvulsants in our patients; however, the MBRN includes information on birth defects and epilepsy during pregnancy. The midwife, general practitioner, or obstetrician reports epilepsy information to the MBRN in the antenatal part of the notification form. The sensitivity of the MBRN for epilepsy is reported to be $72 \%$ compared with records of patient utilization of prescribed anticonvulsants. ${ }^{6}$ The incidence of birth defects was similar between the 2 birth groups, despite the statistical difference in epilepsy between them. Thus, in our limited data set, there was no evidence of an increased risk of birth defects in the offspring of patients with epilepsy and LGG. This can be attributed to the low power to detect rather infrequent birth defects in our study. This is further accentuated by the $72 \%$ sensitivity rate for the MBRN with regard to epilepsy as compared 
TABLE 2. Cox regression with parity after diagnosis entered as a time-varying covariate

\begin{tabular}{|c|c|c|c|c|c|c|}
\hline \multirow[b]{3}{*}{ Parameter } & & & \multicolumn{4}{|c|}{ Adjusted } \\
\hline & \multicolumn{2}{|c|}{ Unadjusted Entire Cohort } & \multicolumn{2}{|c|}{ Entire Cohort } & \multicolumn{2}{|c|}{$\begin{array}{l}\text { Cohort Excluding Patients w/ } \\
\text { Pilocytic Astrocytomas }\end{array}$} \\
\hline & $\mathrm{HR}$ & $95 \% \mathrm{Cl}$ & $\mathrm{HR}$ & $95 \% \mathrm{Cl}$ & $\mathrm{HR}$ & $95 \% \mathrm{Cl}$ \\
\hline \multicolumn{7}{|l|}{ Parity after diagnosis } \\
\hline 0 & Ref & & & & & \\
\hline 1 & 0.500 & $(0.253-0.986)^{*}$ & 0.707 & $(0.353-1.416)$ & 0.731 & $(0.364-1.469)$ \\
\hline$\geq 2$ & 0.204 & $(0.050-0.834)^{*}$ & 0.334 & $(0.080-1.396)$ & 0.339 & $(0.081-1.420)$ \\
\hline \multicolumn{7}{|l|}{ Histology } \\
\hline Astrocytoma & Ref & & & & & \\
\hline Oligoastrocytoma & 0.760 & $(0.369-1.564)$ & 0.822 & $(0.392-1.724)$ & 0.814 & $(0.388-1.710)$ \\
\hline Oligodendroglioma & 0.891 & $(0.614-1.293)$ & 0.911 & $(0.624-1.331)$ & 0.905 & $(0.620-1.321)$ \\
\hline Pilocytic astrocytoma & 0.251 & $(0.117-0.539) \dagger$ & 0.380 & $(0.173-0.831)^{\star}$ & & \\
\hline \multicolumn{7}{|l|}{ Chemotherapy } \\
\hline No & Ref & & & & & \\
\hline Yes & 1.235 & (0.893-1.709) & 0.985 & $(0.687-1.414)$ & 0.931 & $(0.643-1.348)$ \\
\hline Unknown & 1.237 & $(0.733-2.087)$ & 0.725 & $(0.422-1.245)$ & 0.679 & $(0.390-1.183)$ \\
\hline \multicolumn{7}{|l|}{ Radiation therapy } \\
\hline No & Ref & & & & & \\
\hline Yes & 2.013 & $(1.450-2.796) \dagger$ & 1.808 & $(1.262-2.590) \ddagger$ & 1.670 & $(1.159-2.406) \ddagger$ \\
\hline \multicolumn{7}{|l|}{ Surgery } \\
\hline Biopsy & Ref & & & & & \\
\hline Resection & 0.544 & $(0.350-0.843) \ddagger$ & 0.646 & (0.404-1.032) & 0.639 & $(0.395-1.035)$ \\
\hline Unknown & 0.982 & $(0.546-1.767)$ & 1.280 & $(0.698-2.347)$ & 1.277 & $(0.692-2.356)$ \\
\hline Age at diagnosis & 1.067 & $(1.042-1.093) \dagger$ & 1.049 & $(1.022-1.077) \dagger$ & 1.048 & $(1.020-1.076) \dagger$ \\
\hline $\begin{array}{l}\text { ef }=\text { reference category. } \\
p<0.05 \\
p<0.001 \\
p<0.01\end{array}$ & & & & & & \\
\hline
\end{tabular}

with records on patient use of anticonvulsants as detailed in the Norwegian prescription database. ${ }^{6}$ However, other reports that include drug-specific information point out that there are more birth defects related to the use of valproic acid and phenobarbital. ${ }^{18,28}$ Furthermore, they also point out that the teratogenic effect is not only related to the specific compound but also to the dosage used. ${ }^{28}$

In a retrospective Dutch study, seizures in patients with LGG were identified as a significant prognostic factor, and it is often cited that seizures have a positive influence on survival in LGG patients. ${ }^{30}$ However, we did not observe any statistically significant effect of epilepsy as a prognostic factor. This finding is in line with an earlier Norwegian article discussing the effect of epilepsy on outcome in patients with LGG, where the authors found epilepsy to have a prognostic effect only in higher-grade tumors (WHO Grade III and IV). ${ }^{14,15}$ Furthermore, appropriately validated models on LGG patient outcome do not incorporate epilepsy as a significant prognostic factor. ${ }^{3,8,23}$ Thus, we believe the prognostic effects of epilepsy to be modest, if present at all. However, the power to detect an effect of epilepsy on outcome is low in our study.

The patients with LGG in our study had a median survival of 14.3 years. This rivals other reports in which the median survival ranges from approximately 6.5 to 18 years. $3,20,31,32$ This is a rather large range for median survival; however, LGG is a heterogeneous cancer spanning several histopathological entities, and the boundaries between the different WHO grades can be difficult to ascertain despite guidelines on their diagnosis. ${ }^{16}$ Consequently, differences in local pathology reading could explain some of the variation. However, a validation study from University of California, San Francisco, challenges this explanation; the authors incorporated data from 4 different North American centers and found the median overall survival to be quite similar to that in our study. ${ }^{3}$ Another explanation could be differences in the therapeutic approach to treating LGG. There is now ample evidence that the extent of resection is a major prognostic factor in patients with LGG; hence, survival may be influenced by the local attitude toward therapy. 2,10,17,25,27

Pilocytic astrocytomas are usually classified as a WHO Grade I tumor; however, there are also anaplastic pilocytic astrocytomas (WHO Grade III) that are difficult to discern from the usual Grade I tumor using the ICD-O-3 codes. ${ }^{16}$ As expected, LGG patients with pilocytic astrocytomas had a significantly better survival rate than patients with the other LGG entities included in this study. This find- 
TABLE 3. Characteristics of delivery, maternal health, and offspring in patients giving birth before and after LGG diagnosis

\begin{tabular}{|c|c|c|c|c|}
\hline Parameter & $\begin{array}{c}\text { Total No. of } \\
\text { Cases }\end{array}$ & $\begin{array}{c}\text { Births After LGG } \\
\text { Diagnosis }\end{array}$ & $\begin{array}{c}\text { Births Before LGG } \\
\text { Diagnosis }\end{array}$ & $\mathrm{p}$ Value \\
\hline No. of cases & & 95 & 374 & \\
\hline \multicolumn{5}{|l|}{ Mother } \\
\hline Age at parturition (yrs) & 469 & $27 / 30 / 33$ & $22 / 26 / 29$ & $<0.01 \dagger$ \\
\hline Gestational length (wks) ${ }^{*}$ & 433 & $38 / 39 / 40$ & $39 / 40 / 41$ & $<0.01 \dagger$ \\
\hline Epilepsy & 469 & & & $<0.01 \ddagger$ \\
\hline No & & $68.4 \%(65)$ & $97.3 \%(364)$ & \\
\hline Yes & & $31.6 \%(30)$ & $2.7 \%(10)$ & \\
\hline Birth onset & 461 & & & $<0.01 \ddagger$ \\
\hline Vaginal & & $73.6 \%(64)$ & $84.5 \%(316)$ & \\
\hline Induction & & $14.9 \%(13)$ & $12.0 \%(45)$ & \\
\hline Caesarean section & & $11.5 \%(10)$ & $3.5 \%(13)$ & \\
\hline Caesarean section & 59 & & & $0.80 \ddagger$ \\
\hline Elective & & $35 \%(7)$ & $30.8 \%(12)$ & \\
\hline Acute & & $50 \%(10)$ & $46.2 \%(18)$ & \\
\hline Unspecified & & $15 \%(3)$ & $23.1 \%(9)$ & \\
\hline \multicolumn{5}{|l|}{ Baby/Child } \\
\hline Sex & 469 & & & $0.30 \ddagger$ \\
\hline Male & & $47 \%(45)$ & $53.5 \%(200)$ & \\
\hline Female & & $53 \%(50)$ & $46.5 \%(174)$ & \\
\hline Length $(\mathrm{cm})^{*}$ & 454 & $49 / 50 / 51$ & $49 / 50 / 52$ & $0.11 \dagger$ \\
\hline Weight $(g)^{*}$ & 469 & $3195 / 3490 / 3835$ & $3180 / 3510 / 3907$ & $0.61 \dagger$ \\
\hline Head circumference $(\mathrm{cm})^{*}$ & 348 & $35 / 35 / 36$ & $34 / 35 / 36$ & $0.91 \dagger$ \\
\hline Malformation & 469 & & & $0.70 \ddagger$ \\
\hline No & & $95.8 \%(91)$ & $96.5 \%(361)$ & \\
\hline Yes & & $4.2 \%(4)$ & $3.5 \%(13)$ & \\
\hline Child status & 469 & & & $0.41 \ddagger$ \\
\hline Alive & & $98.9 \%(94)$ & $96.8 \%(362)$ & \\
\hline Dead w/in 24 hrs after birth & & $0.0 \%(0)$ & $0.5 \%(2)$ & \\
\hline Dead $>3$ yrs after birth & & $0.0 \%(0)$ & $1.1 \%(4)$ & \\
\hline Stillborn, uncertain time of death & & $1.1 \%(1)$ & $0.2 \%(1)$ & \\
\hline Born alive, uncertain status now & & $0.0 \%(0)$ & $1.3 \%(5)$ & \\
\hline
\end{tabular}

ing is in line with other reports and probably reflects the fact that Grade I lesions can be completely resected more often because of their noninfiltrative nature and thus have a better prognosis than Grade II LGGs. ${ }^{24}$ However, to understand the effect of pregnancy on these more aggressive tumors, we repeated the analysis to include only the Grade II LGGs. In this subset we did not identify a significant effect of pregnancy on patient survival. Thus, pregnancy is not associated with decreased survival in patients with either Grade II LGG or pilocytic astrocytoma.

We identified radiation therapy as a negative factor for survival. The EORTC (European Organisation for Research and Treatment of Cancer) 22845 randomized controlled trial demonstrated a beneficial effect of early radiation therapy on progression-free survival, but not on overall survival. ${ }^{29}$ However, the trial was designed so that radiotherapy was either given early or deferred until tumor progression. Hence, the results indicate that the effect of radiotherapy on overall survival is equivalent when radiotherapy is given early or when deferred until tumor progression. Therefore, our results can be interpreted as the effect of radiotherapy on tumors that have progressed, where there is a large remnant, or where the tumor is symptomatic. Hence, it is reasonable that these patients have a worse prognosis than patients in whom radiotherapy has been deferred. This finding is also in line with another retrospective cohort study identifying radiotherapy as a negative prognostic factor. ${ }^{27}$

\section{Study Strengths and Weaknesses}

Our study is population based and includes 2 large, 
prospectively maintained registries for which reporting is compulsory by law, ensuring that biased selection is highly unlikely. Furthermore, the quality of these registries has been investigated and found to be good. ${ }^{6,9}$

Another major study strength is our ability to identify a number of patients with LGG who subsequently gave birth. Our study includes 65 patients who gave birth after diagnosis and 281 patients who did not give birth after diagnosis. All these patients were in the same age range. Thus, the number of patients and the overlapping age variable allowed the use of multivariable statistical methods to understand the effect of pregnancy on outcome.

A major limitation is that we do not know the extent to which the 2 birth groups differ in their baseline characteristics for known prognostic variables such as tumor size on presentation, eloquence, tumor location, and cognitive status. ${ }^{2,3,14,23}$ Moreover, the CRN does not contain information regarding the extent of resection as an individual prognostic factor. ${ }^{10}$ The analysis does incorporate the effect of histology on survival, but does not include known molecular prognostic factors, such as 1p19q deletion status or mutations in $\mathrm{p} 53$ or $\mathrm{IDH} 1 .{ }^{7}$ Since the study period spans 4 decades, there could also be differences in histopathological criteria for the different tumor entities such that a Grade II tumor early in the study period is designated as Grade III later in the study period. To circumvent this possibility, we performed the same analysis including just the population who received their diagnosis within the last 20 years, yielding essentially the same conclusion (results not shown-results available upon request).

\section{Conclusions}

We conducted the largest study to date investigating the impact of pregnancy on survival in patients with $\mathrm{LGG}$, and we did not identify pregnancy as a significant prognostic factor. Thus, it is reasonable to counsel female patients with LGG who are in their reproductive years that pregnancy does not seem to influence their overall survival. However, the patient must also be thoroughly informed about the reduced expected overall survival associated with LGG, regardless of the decision to become pregnant.

\section{References}

1. Adab N, Tudur SC, Vinten J, Williamson P, Winterbottom $\mathrm{J}$ : Common antiepileptic drugs in pregnancy in women with epilepsy. Cochrane Database Syst Rev (3):CD004848, 2004

2. Capelle L, Fontaine D, Mandonnet E, Taillandier L, Golmard JL, Bauchet L, et al: Spontaneous and therapeutic prognostic factors in adult hemispheric World Health Organization Grade II gliomas: a series of 1097 cases. J Neurosurg 118:1157-1168, 2013

3. Chang EF, Clark A, Jensen RL, Bernstein M, Guha A, Carrabba G, et al: Multiinstitutional validation of the University of California at San Francisco Low-Grade Glioma Prognostic Scoring System. Clinical article. J Neurosurg 111:203-210, 2009

4. Danfors T, Ribom D, Berntsson SG, Smits A: Epileptic seizures and survival in early disease of grade 2 gliomas. Eur J Neurol 16:823-831, 2009

5. Dubin JA, Müller HG, Wang JL: Event history graphs for censored survival data. Stat Med 20:2951-2964, 2001

6. Engeland A, Bjørge T, Daltveit AK, Vollset SE, Furu K:
Validation of disease registration in pregnant women in the Medical Birth Registry of Norway. Acta Obstet Gynecol Scand 88:1083-1089, 2009

7. Figarella-Branger D, Bouvier C, de Paula AM, Mokhtari K, Colin C, Loundou A, et al: Molecular genetics of adult grade II gliomas: towards a comprehensive tumor classification system. J Neurooncol 110:205-213, 2012

8. Gorlia T, Wu W, Wang M, Baumert BG, Mehta M, Buckner JC, et al: New validated prognostic models and prognostic calculators in patients with low-grade gliomas diagnosed by central pathology review: a pooled analysis of EORTC/ RTOG/NCCTG phase III clinical trials. Neuro Oncol 15:1568-1579, 2013

9. Helseth A, Langmark F, Mørk SJ: Neoplasms of the central nervous system in Norway. I. Quality control of the registration in the Norwegian Cancer Registry. APMIS 96:10021008,1988

10. Jakola AS, Myrmel KS, Kloster R, Torp SH, Lindal S, Unsgård G, et al: Comparison of a strategy favoring early surgical resection vs a strategy favoring watchful waiting in low-grade gliomas. JAMA 308:1881-1888, 2012

11. Kohler BA, Ward E, McCarthy BJ, Schymura MJ, Ries LA, Eheman C, et al: Annual report to the nation on the status of cancer, 1975-2007, featuring tumors of the brain and other nervous system. J Natl Cancer Inst 103:714-736, 2011

12. Larsen IK, Småstuen M, Johannesen TB, Langmark F, Parkin DM, Bray F, et al: Data quality at the Cancer Registry of Norway: an overview of comparability, completeness, validity and timeliness. Eur J Cancer 45:1218-1231, 2009

13. Liigant A, Haldre S, Oun A, Linnamägi U, Saar A, Asser T, et al: Seizure disorders in patients with brain tumors. Eur Neurol 45:46-51, 2001

14. Lote K, Egeland T, Hager B, Stenwig B, Skullerud K, BergJohnsen J, et al: Survival, prognostic factors, and therapeutic efficacy in low-grade glioma: a retrospective study in 379 patients. J Clin Oncol 15:3129-3140, 1997

15. Lote K, Stenwig AE, Skullerud K, Hirschberg H: Prevalence and prognostic significance of epilepsy in patients with gliomas. Eur J Cancer 34:98-102, 1998

16. Louis DN, Ohgaki H, Wiestler OD, Cavenee WK, Burger PC, Jouvet A, et al: WHO classification of tumours of the central nervous system. Acta Neuropathol 114:97-109, 2007

17. McGirt MJ, Chaichana KL, Attenello FJ, Weingart JD, Than $\mathrm{K}$, Burger PC, et al: Extent of surgical resection is independently associated with survival in patients with hemispheric infiltrating low-grade gliomas. Neurosurgery 63:700-708, 2008

18. Meador KJ, Baker GA, Browning N, Cohen MJ, Bromley RL, Clayton-Smith J, et al: Fetal antiepileptic drug exposure and cognitive outcomes at age 6 years (NEAD study): a prospective observational study. Lancet Neurol 12:244-252, 2013

19. Pallud J, Duffau H, Razak RA, Barbarino-Monnier P, Capelle L, Fontaine D, et al: Influence of pregnancy in the behavior of diffuse gliomas: clinical cases of a French glioma study group. J Neurol 256:2014-2020, 2009

20. Pallud J, Fontaine D, Duffau H, Mandonnet E, Sanai N, Taillandier L, et al: Natural history of incidental World Health Organization grade II gliomas. Ann Neurol 68:727733,2010

21. Pallud J, Mandonnet E, Deroulers C, Fontaine D, Badoual M, Capelle L, et al: Pregnancy increases the growth rates of World Health Organization grade II gliomas. Ann Neurol 67:398-404, 2010

22. Pallud J, Taillandier L, Capelle L, Fontaine D, Peyre M, Ducray F, et al: Quantitative morphological magnetic resonance imaging follow-up of low-grade glioma: a plea for systematic measurement of growth rates. Neurosurgery 71:729-740, 2012

23. Pignatti F, van den Bent M, Curran D, Debruyne C, Sylvester 
$\mathrm{R}$, Therasse P, et al: Prognostic factors for survival in adult patients with cerebral low-grade glioma. J Clin Oncol 20:2076-2084, 2002

24. Pollack IF, Claassen D, al-Shboul Q, Janosky JE, Deutsch M: Low-grade gliomas of the cerebral hemispheres in children: an analysis of 71 cases. J Neurosurg 82:536-547, 1995

25. Sanai N, Berger MS: Operative techniques for gliomas and the value of extent of resection. Neurotherapeutics 6:478486, 2009

26. Sanai N, Chang S, Berger MS: Low-grade gliomas in adults. J Neurosurg 115:948-965, 2011

27. Smith JS, Chang EF, Lamborn KR, Chang SM, Prados MD, Cha S, et al: Role of extent of resection in the long-term outcome of low-grade hemispheric gliomas. J Clin Oncol 26:1338-1345, 2008

28. Tomson T, Battino D: Teratogenic effects of antiepileptic drugs. Lancet Neurol 11:803-813, 2012

29. van den Bent MJ, Afra D, de Witte O, Ben Hassel M, Schraub S, Hoang-Xuan K, et al: Long-term efficacy of early versus delayed radiotherapy for low-grade astrocytoma and oligodendroglioma in adults: the EORTC 22845 randomised trial. Lancet 366:985-990, 2005

30. van Veelen ML, Avezaat CJ, Kros JM, van Putten W, Vecht C: Supratentorial low grade astrocytoma: prognostic factors, dedifferentiation, and the issue of early versus late surgery. J Neurol Neurosurg Psychiatry 64:581-587, 1998

31. Yang P, Wang Y, Peng X, You G, Zhang W, Yan W, et al: Management and survival rates in patients with glioma in China (2004-2010): a retrospective study from a single-institution. J Neurooncol 113:259-266, 2013
32. Youland RS, Schomas DA, Brown PD, Nwachukwu C, Buckner JC, Giannini C, et al: Changes in presentation, treatment, and outcomes of adult low-grade gliomas over the past fifty years. Neuro Oncol 15:1102-1110, 2013

33. Zwinkels H, Dörr J, Kloet F, Taphoorn MJ, Vecht CJ:

Pregnancy in women with gliomas: a case-series and review of the literature. J Neurooncol 115:293-301, 2013

\section{Disclosures}

The authors report no conflict of interest concerning the materials or methods used in this study or the findings specified in this paper.

\section{Author Contributions}

Conception and design: Rønning. Acquisition of data: Helseth, Meling, Johanessen, Rønning. Analysis and interpretation of data: Rønning, Johanessen. Drafting the article: Rønning. Critically revising the article: all authors. Reviewed submitted version of manuscript: all authors. Approved the final version of the manuscript on behalf of all authors: Rønning. Statistical analysis: Rønning. Administrative/technical/material support: Helseth, Meling, Johanessen. Study supervision: Helseth, Johanessen.

\section{Correspondence}

Pål Rønning, Department of Neurosurgery, Oslo University Hospital, P.O. Box 4950 Nydalen, Oslo 0424, Norway. email: palronning@gmail.com. 